\title{
The dietary flavonol fisetin enhances the apoptosis-inducing potential of TRAIL in prostate cancer cells
}

\author{
EWELINA SZLISZKA ${ }^{1}$, KRZYSZTOF J. HELEWSKI $^{2}$, ELZBIETA MIZGALA $^{3}$ and WOJCIECH KROL ${ }^{1}$ \\ Departments of ${ }^{1}$ Microbiology and Immunology, ${ }^{2}$ Histology and Embryology, ${ }^{3}$ Family Medicine, \\ Medical University of Silesia in Katowice, 41808 Zabrze, Poland
}

Received March 12, 2011; Accepted May 17, 2011

DOI: $10.3892 / \mathrm{ijo} .2011 .1116$

\begin{abstract}
Tumour necrosis factor-related apoptosis-inducing ligand (TRAIL) is an endogenous agent that induces apoptosis selectively in cancer cells. Soluble or expressed in immune cells, TRAIL plays an important role in the defense against tumour cells. The resistance of cancer cells to TRAIL immune surveillance is implicated in tumour development. Naturally occurring flavonoids can sensitize TRAIL-resistant cancer cells and augment their apoptotic activity. Fisetin, a dietary flavonol has cancer preventive properties. This study was designed to investigate the effect of fisetin on the TRAILinduced apoptosis potential in prostate cancer cells. Prostate cancer cell lines represent an ideal model for research in chemoprevention. Cytotoxicity was measured by MTT and LDH assays. Apoptosis was detected using Annexin V-FITC by flow cytometry and fluorescence microscopy. Mitochondrial membrane potential $(\Delta \Psi \mathrm{m})$ was evaluated using DePsipher staining by fluorescence microscopy. Death receptor (TRAIL-R1 and TRAIL-R2) expression was analysed by flow cytometry. Inhibition of NF- $\mathrm{KB}$ (p65) activation was confirmed with an ELISA-based TransAM NF- $\kappa$ B kit. Caspase-8 and caspase- 3 activities were determined by colorimetric protease assays. Our study demonstrates that fisetin sensitizes the TRAIL-resistant androgen-dependent $\mathrm{LNCaP}$ and the androgen-independent DU145 and PC3 prostate cancer cells to TRAIL-induced death. Fisetin augmented TRAIL-mediated cytotoxicity and apoptosis in prostate cancer LNCaP cells by engaging the extrinsic (receptor-mediated) and intrinsic (mitochondrial) apoptotic pathways. Fisetin increased the expression of TRAIL-R1 and decreased the activity of NF- $\kappa B$. Co-treatment of cancer cells with TRAIL and fisetin caused significant activation of caspase- 8 and caspase- 3 and
\end{abstract}

Correspondence to: Professor Wojciech Krol, Department of Microbiology and Immunology, Medical University of Silesia in Katowice, Jordana 19, 41808 Zabrze, Poland

E-mail: wkrol@sum.edu.pl

Key words: tumour necrosis factor-related apoptosis-inducing ligand, fisetin, apoptosis, prostate cancer, chemoprevention disruption of $\Delta \Psi \mathrm{m}$. Our data indicate the usefulness of fisetin in prostate cancer chemoprevention through enhancement of TRAIL-mediated apoptosis.

\section{Introduction}

Tumour necrosis factor-related apoptosis-inducing ligand (TRAIL) triggers apoptosis in cancer cells with no toxicity toward normal tissues. TRAIL plays an important role in immune surveillance and in the defence against tumour cells. This death ligand is expressed on the surface of T lymphocytes, natural killer cells, dendritic cells, neutrophils, monocytes, macrophages and can be cleaved into a soluble, secreted form (1-3). TRAIL is a promising antitumour agent capable of killing cancer cells via receptor-mediated (extrinsic) programmed death. TRAIL binds to death receptor TRAIL-R1 (DR4) and/or TRAIL-R2 (DR5), which promotes the recruitment of the adaptor molecule Fas-associated death domain (FADD) to form the death inducing signalling complex (DISC) and activate caspase- 8 . Crosstalk exists between the extrinsic and intrinsic (mitochondrial-dependent) apoptosis pathways. Activation of caspase- 8 directly leads to the activation of caspase-3, causing cell death, and simultaneously, BH3-interacting domain death agonist (Bid) cleavage along with cytochrome c release and mitochondrial membrane potential disruption $(4,5)$. However, some tumour cells are resistant to TRAIL-induced cytotoxicity. Failure to undergo apoptosis has been implicated in the resistance of cancer cells to TRAIL surveillance and therefore in tumour development. The expression of the death receptors and proapoptotic or antiapoptotic proteins in cancer cells is involved in TRAILresistance (1-8). Studies of our group as well as of other researchers have shown that TRAIL-resistant cancer cells can be sensitized to TRAIL-mediated apoptosis by flavonoids (9-16).

Flavonoids, a family of polyphenolic compounds, are commonly found in fruits and vegetables. They are subdivided into several groups, including flavonols, flavonones, flavones, flavanols, isoflavones and anthocyanidins. As natural products, flavonoids are regarded as safe and easily obtainable in routine diet, a fact that makes them ideal cancer chemopreventive agents (3,17-19). Fisetin (3,3',4',7-tertahydroxyflavone) is a flavonol present in apple, strawberry, grape, kiwi fruit, persimmon, cucumber and onion. The structure of the 
compound is presented in Fig. 1. Fisetin induces apoptosis and cell cycle arrest in prostate cancer LNCaP, DU145 and PC3 cells, with minimal effects on normal prostate epithelial cells (20-23). The treatment of athymic nude mice with this flavonol results in inhibition of CWR22Rv1-based prostate tumour xenograft growth (24).

Chemopreventive intervention using naturally occurring dietary agents is an attractive option in prostate cancer because of its incidence, prevalence, and disease-related morbidity and mortality $(20,25,26)$. Epidemiological studies have demonstrated an inverse association between flavonoid intake and prostate cancer risk $(17,27)$. Flavonoids exert their chemopreventive activity through the modulation of apoptotic signalling pathways (17). We show here that fisetin markedly augments TRAIL-mediated apoptosis in prostate cancer cells. This dietary flavonol sensitizes androgen-dependent LNCaP cells and androgen-independent DU145, PC3 cells to TRAILinduced apoptosis.

\section{Materials and methods}

Prostate cancer cell culture. Human androgen-dependent LNCaP, androgen-independent DU145 and androgen-independent $\mathrm{PC} 3$ prostate cancer cell lines were obtained from the German Collection of Microorganisms and Cell Cultures (DSMZ, Braunschweig, Germany). The LNCaP and DU145 cells were maintained in RPMI-1640 medium. The PC3 cells were grown in RPMI-1640 with the addition of Ham's medium. The media for prostate cell cultures were supplemented with $10 \%$ heat-inactivated fetal bovine serum, $4 \mathrm{mM} \mathrm{L}$-glutamine, $100 \mathrm{U} / \mathrm{ml}$ penicillin and $100 \mu \mathrm{g} / \mathrm{ml}$ streptomycin. The cells were incubated at $37^{\circ} \mathrm{C}$ in a humidified atmosphere of $5 \% \mathrm{CO}_{2}$ $(27,28)$. All reagents for cell culture were purchased from PAA, The Cell Culture Company (Pasching, Austria).

Reagents. Fisetin was obtained from Aldrich Chemical Co., Inc. (Milwaukee, WI, USA). The flavonoid was dissolved in DMSO (dimethyl sulfoxide) to obtain the working concentrations. Soluble recombinant human TRAIL was purchased from PeproTech, Inc. (Rocky Hill, NJ, USA). The human recombinant chimeric proteins TRAIL-R $1 / \mathrm{Fc}$ and TRAIL-R2/Fc, the general caspase inhibitor Z-VAD-FMK, the caspase-8 inhibitor Z-IETD-FMK, and the caspase-3 inhibitor Z-DEVD-FMK were obtained from R\&D Systems (Minneapolis, MN, USA).

Cytotoxicity assay. Cytotoxicity was measured by the 3-(4,5-dimethyl-2-thiazyl)-2,5-diphenyl-2H-tetrazolium bromide (MTT) assay $(29,30)$. The MTT assay is based on the cleavage of the tetrazolium salt MTT by viable cells to a blue formazan dye. LNCaP cells $\left(2 \times 10^{5} / \mathrm{ml}\right)$, DU145 cells $\left(1 \times 10^{5} / \mathrm{ml}\right)$ and PC3 $\left(1 \times 10^{5} / \mathrm{ml}\right)$ cells were seeded in a 96-well plate for $24 \mathrm{~h}$ before the experiments. Then the cells were incubated with TRAIL (20-200 ng/ml) and/or fisetin (10-50 $\mu \mathrm{M})$. After $24 \mathrm{~h}, 20 \mu \mathrm{l}$ of MTT solution $(5 \mathrm{mg} / \mathrm{ml})$ was added to each well for $4 \mathrm{~h}$. The resulting blue formazan crystals were dissolved in DMSO. These reagents were purchased from Sigma Chemical Co. (St. Louis, MO, USA). Controls included native cells and medium alone. The spectrophotometric absorbance at $550 \mathrm{~nm}$ wavelength was measured using a microplate reader (ELx 800)

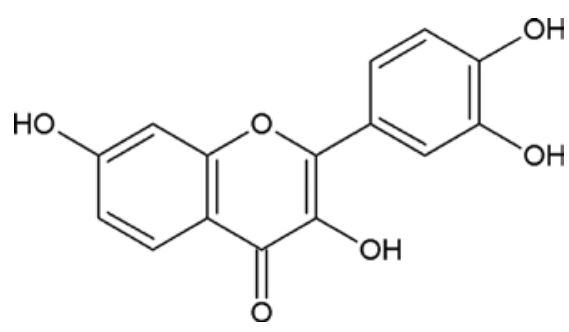

Figure 1. Chemical structure of fisetin.

(Bio-Tek Instruments, Inc., Winooski, VT, USA). The percent cytotoxicity was calculated by the following formula: percent cytotoxicity $($ cell death $)=(1-$ absorbance of experimental wells/absorbance of control wells]) x $100 \%$.

Lactate dehydrogenase release assay. Lactate dehydrogenase $(\mathrm{LDH})$ is a stable cytosolic enzyme that is released upon membrane damage in necrotic cells. LDH activity was measured using a cytotoxicity assay kit (Roche Diagnostics $\mathrm{GmbH}$, Mannheim, Germany) (30,31). Prostate cancer cells were treated with TRAIL $(20-200 \mathrm{ng} / \mathrm{ml})$ and/or fisetin $(10-50 \mu \mathrm{M})$ for the indicated period of time. LDH released in culture supernatants was detected with a coupled enzymatic assay, resulting in the conversion of a tetrazolium salt into a red formazan product. The spectrophotometric absorbance at $490 \mathrm{~nm}$ was measured using a microplate reader. Maximal release was obtained after treating control cells with $1 \%$ Triton X-100 (Sigma Chemical Co.) for $10 \mathrm{~min}$ at room temperature. The necrotic percentage was expressed using the following formula: (sample value/ maximal release) x $100 \%$.

Detection of apoptosis by flow cytometry. Apoptosis was determined by flow cytometry using the Apoptest-FITC kit with Annexin V (Dako, Glostrup, Denmark). LNCaP cells ( $2 \times 10^{5} /$ $\mathrm{ml})$, DU145 cells $\left(1 \times 10^{5} / \mathrm{ml}\right)$ and PC 3 cells $\left(1 \times 10^{5} / \mathrm{ml}\right)$ were seeded in 24-well plates for $24 \mathrm{~h}$ and then exposed to TRAIL $(20-100 \mathrm{ng} / \mathrm{ml})$ and/or fisetin $(10-50 \mu \mathrm{M})$ for $24 \mathrm{~h}$. After this incubation, the cancer cells were washed twice with phosphatebuffered saline solution (PBS) and resuspended in $1 \mathrm{ml}$ of binding buffer. The cell suspension $(500 \mu \mathrm{l})$ was then incubated with $5 \mu \mathrm{l}$ of Annexin V-FITC and $10 \mu \mathrm{l}$ of propidium iodide (PI) for $10 \mathrm{~min}$ at room temperature in the dark. The population of Annexin V-positive cells was evaluated by flow cytometry (BD FACScan, Becton-Dickinson Immunocytometry Systems, San Jose, CA, USA) $(31,32)$.

Detection of apoptosis by fluorescence microscopy. Apoptotic cells were quantified using the fluorescence microscopy method of the Apoptotic and Necrotic and Healthy Cells Quantification kit from Biotium, Inc. (Hayward, CA, USA) $(15,33)$. LNCaP cells ( $\left.2 \times 10^{5} / \mathrm{ml}\right)$, DU145 cells $\left(1 \times 10^{5} / \mathrm{ml}\right)$ and PC 3 cells $\left(1 \times 10^{5} / \mathrm{ml}\right)$ were seeded in 24-well plates for $24 \mathrm{~h}$ before the experiments. TRAIL $(100 \mathrm{ng} / \mathrm{ml})$ and/or fisetin $(50 \mu \mathrm{M})$ were added to the cancer cells, and $24 \mathrm{~h}$ later, the cells were washed with PBS and detached from the cell culture wells with trypsin. Next, the cells were centrifuged to discard the supernatant, washed with PBS and resuspended in binding buffer (100 $\mu \mathrm{l} / \mathrm{sample})$. A combination of $5 \mu \mathrm{l}$ of Annexin V-FITC, $5 \mu \mathrm{l}$ of ethidium homodimer III and $5 \mu 1$ of Hoechst 33342 solution was added 
to each tube. The samples were incubated at room temperature for $15 \mathrm{~min}$ in the dark. After staining, the cancer cells were washed with binding buffer, placed on a glass slide and covered with a glass coverslip. The stained cells were observed under an IX51 fluorescence inverted microscope (Olympus, Tokyo, Japan) using filter sets for FITC, TRITC and DAPI. The cells were counted, and the number of apoptotic cells was expressed as a percentage of the total cells.

Flow cytometric analysis of death receptor expression on the cell surface. The cell surface expression of death receptors TRAIL-R1 and TRAIL-R2 on LNCaP cells was determined by flow cytometry (BD FACSCanto, Becton-Dickinson Immunocytometry Systems). LNCaP cells $\left(2 \times 10^{5} / \mathrm{ml}\right)$ were seeded in 24-well plates for $24 \mathrm{~h}$ and then exposed to fisetin $(50 \mu \mathrm{M})$ for $24 \mathrm{~h}$. Cells were then harvested using trypsin and ethylenediaminetetraacetic acid (EDTA), washed twice in PBS and resuspended in PBS containing $0.5 \%$ bovine serum albumin (BSA). Cells were incubated with $10 \mu 1$ phycoerythrin-conjugated anti-TRAIL-R1 or anti-TRAIL-R2 monoclonal antibodies (R\&D Systems) at $4^{\circ} \mathrm{C}$ for $45 \mathrm{~min}$. After staining, the cancer cells were washed with PBS and finally analysed by flow cytometry (35-37). The control consisted of cells in a separate tube treated with phycoerythrinlabelled mouse $\operatorname{IgG}_{1}$ or mouse $\operatorname{IgG}_{2 \mathrm{~B}}$ (R\&D Systems).

Caspase activity assays. Caspase- 3 and caspase- 8 activities were assessed by colorimetric protease assay kits (R\&D Systems). The tests are based on the spectrophotometric detection of the chromophore p-nitroanaline (pNA) after cleavage from the caspase substrate (a caspase-specific peptide conjugated to pNA). LNCaP cells $\left(1 \times 10^{6} / \mathrm{ml}\right)$ were seeded in Petri dishes $24 \mathrm{~h}$ before the experiments. TRAIL $(100 \mathrm{ng} / \mathrm{ml})$ and/or fisetin $(50 \mu \mathrm{M})$ were added to the cancer cells, and $24 \mathrm{~h}$ later, the cells were washed with PBS and detached from the cell culture wells by trypsin. The cells were centrifuged to discard the supernatant and treated with lysis buffer. The cell lysates were tested for protease activity by the addition of a labelled caspase substrate, DEVD-pNA for caspase-3 activity and IETD-pNA for caspase-8 activity. pNA absorbance was quantified using a spectrophotometer V-630 (Jasco International Co., Tokyo, Japan) at a wavelength of $405 \mathrm{~nm}$ (38).

Evaluation of the mitochondrial membrane potential by DePsipher. The DePsipher kit (R\&D Systems) was used to measure the mitochondrial membrane potential under a fluorescence microscope $(34,35)$. LNCaP cells $\left(2 \times 10^{5} / \mathrm{ml}\right)$ were seeded in a 24 -well plate $24 \mathrm{~h}$ prior to the experiments. TRAIL (100 ng/ml) and/or fisetin $(50 \mu \mathrm{M})$ were added, and $24 \mathrm{~h}$ later, the cells were washed with PBS and detached from the cell culture wells with trypsin. The cells were incubated in the dark with DePsipher (5,5',6,6'-tetrachloro-1,1',3,3'-tetraethylbenzimidazolyl carbocyanin iodide) solution at a concentration of $5 \mu \mathrm{g} / \mathrm{ml}$ for $30 \mathrm{~min}$ at $37^{\circ} \mathrm{C}$, washed with reaction buffer with stabiliser, placed on a glass slide and covered with a glass coverslip. The stained cells were observed under a fluorescence inverted microscope using filter sets for FITC and TRITC. DePsipher visualizes the potential-dependent accumulation in mitochondria, indicated by a fluorescence emission shift from red $(590 \mathrm{~nm})$ to green $(530 \mathrm{~nm})$.
The activity of $N F-\kappa B$. The NF- $\kappa \mathrm{B}$ activity in nuclear extracts was measured using the ELISA-based TransAM NF- $\kappa$ B kit (Active Motif Europe, Rixensart, Belgium). LNCaP cells $\left(1 \times 10^{6} / \mathrm{ml}\right)$ were seeded in Petri dishes $24 \mathrm{~h}$ before the experiments. Fisetin $(50 \mu \mathrm{M})$ with or without TRAIL $(100 \mathrm{ng} / \mathrm{ml})$ was added to the cancer cells, and $24 \mathrm{~h}$ later, the cells were washed with PBS and detached from the cell culture wells by trypsin treatment. The commercially available Nuclear Extract kit was obtained from Active Motif Europe for the preparation of LNCaP cell nuclear extracts. The TransAM $\mathrm{NF}$-assay for $\mathrm{NF}-\kappa \mathrm{B}$ (p65) activity was performed according to the vendor's protocol $(35,37)$. NF- $\kappa \mathrm{B}$ DNA-binding activity was assessed using the ELISA kit for the transcription factor p65. Oligonucleotides containing the NF- $\kappa$ B consensus site (5'-GGGACTTCC-3') were immobilised on a 96-well plate. The active forms of $\mathrm{NF}-\kappa \mathrm{B}$ in the nuclear extracts were bound to the oligonucleotides on the plate and detected colourimetrically by spectrophotometry at an absorbance of $450 \mathrm{~nm}$ and with a reference wavelength of $650 \mathrm{~nm}$. The detection limit for the TransAM NF- $\kappa$ B kit is $<0.4 \mathrm{ng} / \mathrm{ml}$ purified $\mathrm{p} 65$.

Statistical analysis. The results are expressed as the mean \pm SD obtained from three independent experiments performed in quadruplicate $(n=12)$ or duplicate $(n=6)$. The statistical significance was evaluated using the Bartlett $\chi^{2}$ test followed by analysis of variance (ANOVA) and post-hoc test. The expression of death receptors was assessed using the Levene test followed by the Mann-Whitney U-test. A P-value $<0.05$ was considered significant.

\section{Results}

Cytotoxic and apoptotic effects of TRAIL in combination with fisetin in the androgen-dependent LNCaP prostate cancer cells. The cytotoxic effect of TRAIL at the concentrations of $20-100 \mathrm{ng} / \mathrm{ml}$ after $24-\mathrm{h}$ incubation ranged from $3.8 \pm 1.4 \%$ with the lowest concentration to $14.2 \pm 1.2 \%$ cell death with the highest concentration. The death ligand at the same concentrations induced apoptosis ranging from $7.5 \pm 0.9$ to $16.8 \pm 0.9 \%$ in prostate cancer cells. TRAIL concentrations higher than $100 \mathrm{ng} / \mathrm{ml}$ resulted in no significant increase in apoptotic activity. LNCaP cells were resistant to TRAILmediated cytotoxicity and apoptosis. We next investigated the cytotoxic and apoptotic effects of TRAIL in combination with fisetin on LNCaP cells. After $24 \mathrm{~h}$ of co-treatment of cancer cells with TRAIL at concentrations of 20-100 ng/ml and flavonol at concentrations of $10-50 \mu \mathrm{M}$ the cytotoxicity ranged from $25.2 \pm 1.0 \%(10 \mu \mathrm{M}$ fisetin plus $20 \mathrm{ng} / \mathrm{ml} \mathrm{TRAIL})$ to $81.2 \pm 1.6 \%(50 \mu \mathrm{M}$ fisetin plus $100 \mathrm{ng} / \mathrm{ml}$ TRAIL). The cytotoxicity measured by the MTT assay is shown in Fig. 2A. We found that fisetin synergized with TRAIL to induce apoptosis in cancer cells. The percentage of apoptotic cells stained with Annexin V-FITC detected by flow cytometry after a 24-h exposure to TRAIL at $50-100 \mathrm{ng} / \mathrm{ml}$ in combination with $20-50 \mu \mathrm{M}$ fisetin was elevated to $61.6 \pm 1.0-80.6 \pm 1.1 \%$ (Fig. 2B). Fisetin sensitized TRAIL-resistant LNCaP cells to TRAIL-mediated apoptosis. The necrotic cell death percentage of LNCaP cells examined by the Apoptest-FITC and the LDH assays was nearly zero. The Annexin V-FITC staining visualised by fluorescence microscopy supports the 

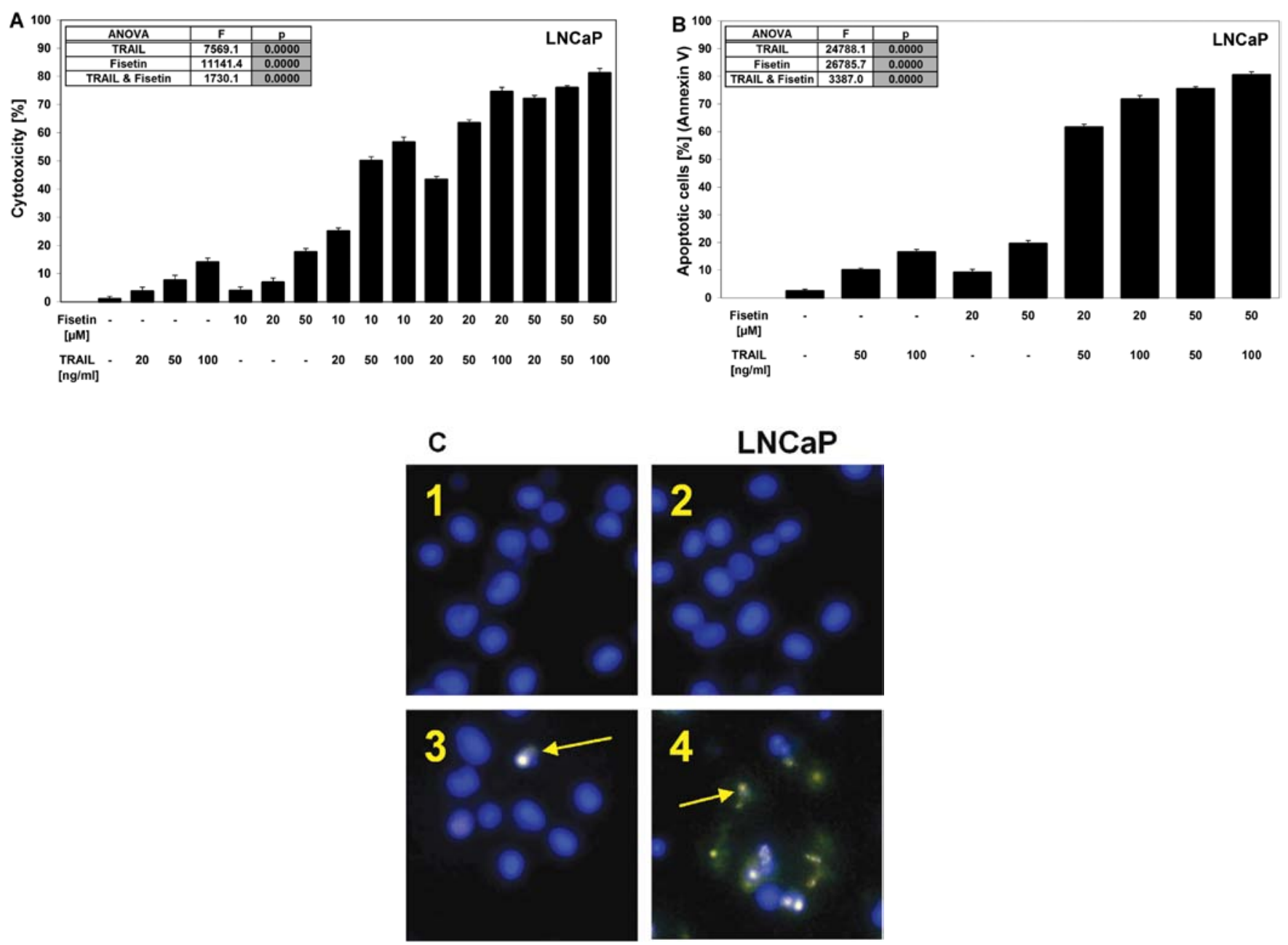

Figure 2. Cytotoxic and apoptotic effects of TRAIL in combination with fisetin in the androgen-dependent prostate cancer cells. (A) The cytotoxic activity of TRAIL in combination with fisetin in LNCaP cells. Cells were incubated for $24 \mathrm{~h}$ with TRAIL at concentrations of $20-100 \mathrm{ng} / \mathrm{ml}$ and/or fisetin at concentrations of 10-50 $\mu \mathrm{M}$. The percentage of cell death was measured using the MTT cytotoxicity assay. The values represent the mean \pm SD of three independent experiments performed in quadruplicate $(\mathrm{n}=12)(\mathrm{P}<0.0001$ TRAIL + fisetin compared to TRAIL or fisetin alone in ANOVA). (B) TRAILinduced apoptosis in combination with fisetin in LNCaP cells. Cells were incubated for $24 \mathrm{~h}$ with TRAIL at concentrations of 50-100 ng/ml and/or fisetin at concentrations of 20-50 $\mu \mathrm{M}$. Apoptotic cell death was detected by flow cytometry using Annexin V-FITC staining. The values represent the mean \pm SD of three independent experiments performed in duplicate $(\mathrm{n}=6)(\mathrm{P}<0.0001$ for TRAIL + fisetin compared to TRAIL or fisetin alone in ANOVA). (C) TRAILinduced apoptosis in combination with fisetin in LNCaP cells: (1) control cells, (2) cells incubated with $100 \mathrm{ng} / \mathrm{ml}$ TRAIL, (3) cells incubated with $50 \mu \mathrm{M}$ fisetin and (4) cells incubated with both $100 \mathrm{ng} / \mathrm{ml}$ TRAIL and $50 \mu \mathrm{M}$ fisetin. Apoptotic cell death was detected and visualised by fluorescence microscopy using Annexin V-FITC staining. Healthy cells (stained with Hoechst 33342) emitted blue fluorescence, and apoptotic cells (stained with Hoechst 33342 and Annexin V-FITC) emitted green and blue fluorescence (indicated by arrows).

augmentation of the apoptotic activity of TRAIL by fisetin against LNCaP cells (Fig. 2C).

Cytotoxic and apoptotic effects of TRAIL in combination with fisetin in the androgen-independent DU145 and PC3 prostate cancer cells. The cells were incubated with $100 \mathrm{ng} / \mathrm{ml}$ TRAIL for $24 \mathrm{~h}$. The cytotoxicity of TRAIL was $5.5 \pm 1.4 \%$ in the DU145 cells and $4.1 \pm 1.0 \%$ in the PC 3 cells. Exposure of DU145 and PC3 cells to $100 \mathrm{ng} / \mathrm{ml}$ TRAIL resulted in the presence of $7.5 \pm 0.6 \%$ and $7.1 \pm 0.7 \%$ of apoptotic cells, respectively. Both androgen-independent prostate cancer cell lines were resistant to TRAIL. The co-treatment of cancer cells with $100 \mathrm{ng} / \mathrm{ml}$ TRAIL and $50 \mu \mathrm{M}$ fisetin increased the percentage of cell death to $58.1 \pm 2.2 \%$ for DU145 cells and to $50.1 \pm 1.1 \%$ for PC3 cells (Fig. 3A and B). TRAIL in combination with $50 \mu \mathrm{M}$ fisetin induced $55.3 \pm 1.2 \%$ apoptosis in DU145 cells and $50.8 \pm 1.1 \%$ in PC3 cells (Fig. 3C and D). Annexin V-staining visualised by fluorescence microscopy was used to demonstrate these effects (Fig. 3E and F). The necrotic cell death percentage of cancer cells examined by the Apoptest-FITC and the LDH assays was nearly zero. Fisetin enhanced the apoptosis-inducing potential of TRAIL and sensitized the prostate cancer DU145 and PC3 cells.

Effects of fisetin on death receptor expression in LNCaP cells. The expression of death receptors on the cell surface is critical for TRAIL-mediated apoptosis. We therefore, analysed the expression of TRAIL-R1 and TRAIL-R2 in LNCaP cells after a 24-h treatment with $50 \mu \mathrm{M}$ fisetin by flow cytometry (Fig. 4). Fisetin significantly increased the expression of TRAIL-R1 in prostate cancer cells, but TRAIL-R2 expression was unaltered. Fisetin enhanced the apoptotic effect of TRAIL through the intrinsic apoptosis pathway. To confirm that the apoptosis induced by co-treatment with TRAIL and fisetin 

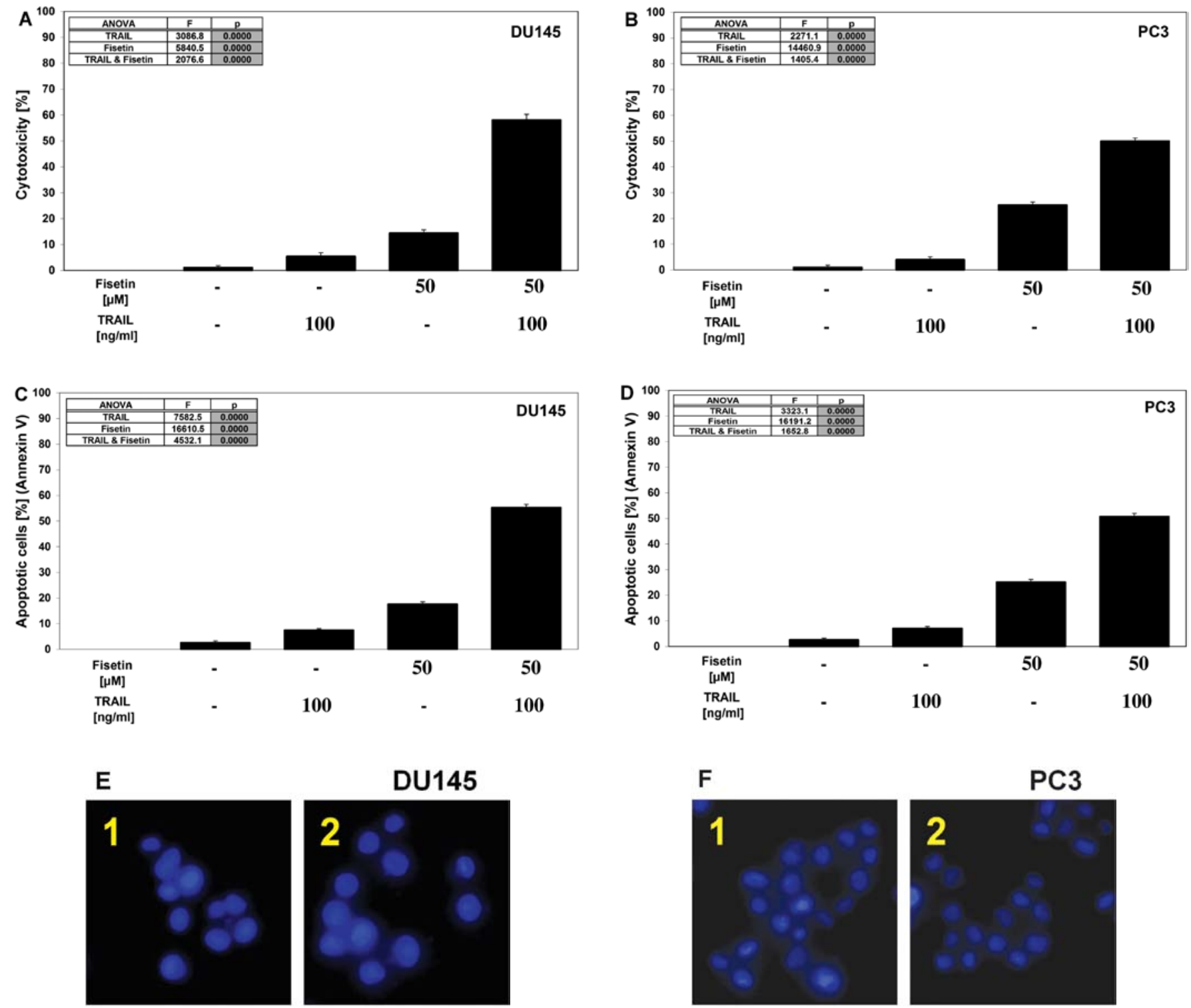

$\mathbf{F}$
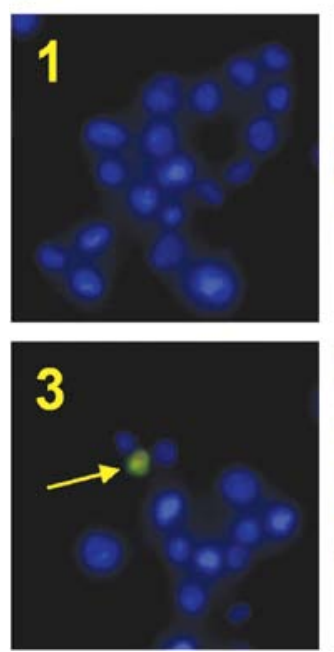
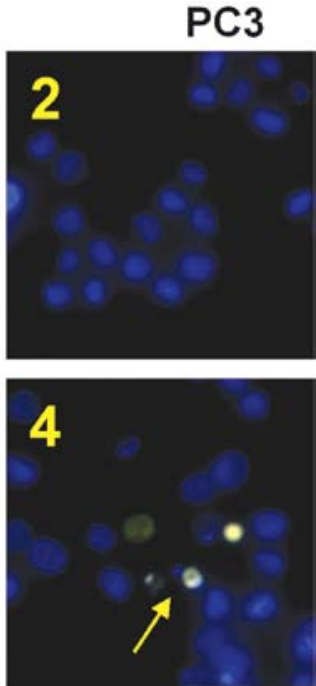

Figure 3. Cytotoxic and apoptotic effects of TRAIL in combination with fisetin in androgen-independent prostate cancer cells. Cells were incubated for $24 \mathrm{~h}$ with TRAIL at a concentration of $100 \mathrm{ng} / \mathrm{ml}$ and/or fisetin at concentration of $50 \mu \mathrm{M}$. The cytotoxic activity of TRAIL in combination with fisetin in (A) DU145 cells and (B) PC3 cells. The percentage of cell death was measured using the MTT cytotoxicity assay. The values represent the mean \pm SD of three independent experiments performed in quadruplicate $(n=12)(P<0.0001$ for TRAIL + fisetin compared to TRAIL or fisetin alone in ANOVA). TRAILinduced apoptosis in combination with fisetin in (C) DU145 and (D) PC3 cells. Apoptotic cell death was detected by flow cytometry using Annexin V-FITC staining. The values represent the mean $\pm \mathrm{SD}$ of three independent experiments performed in duplicate $(\mathrm{n}=6)(\mathrm{P}<0.0001$ for TRAIL + fisetin compared to TRAIL or fisetin alone in ANOVA). TRAIL-induced apoptosis in combination with fisetin in (E) DU145 cells and (F) PC3 cells: (1) control cells, (2) cells incubated with $100 \mathrm{ng} / \mathrm{ml}$ TRAIL, (3) cells incubated with $50 \mu \mathrm{M}$ fisetin, and (4) cells incubated with both $100 \mathrm{ng}$ ml TRAIL and $50 \mu \mathrm{M}$ fisetin. Apoptotic cell death was detected and visualised by fluorescence microscopy using Annexin V-FITC staining. Healthy cells (stained with Hoechst 33342) emitted blue fluorescence, and apoptotic cells (stained with Hoechst 33342 and Annexin V-FITC) emitted green and blue fluorescence (indicated by arrows).

was mediated through TRAIL-R1, we used the TRAIL-R1/Fc chimeric protein, which has a dominant negative function against TRAIL-R1. The protein efficiently blocked apoptosis caused by the co-treatment of TRAIL and fisetin.
Effects of TRAIL and fisetin on caspase-8 and caspase-3 activities in LNCaP cells. The cells were treated with $100 \mathrm{ng} / \mathrm{ml}$ TRAIL and/or $50 \mu \mathrm{M}$ fisetin for the indicated period of time. The stimulation of death receptors induces DISC formation, 

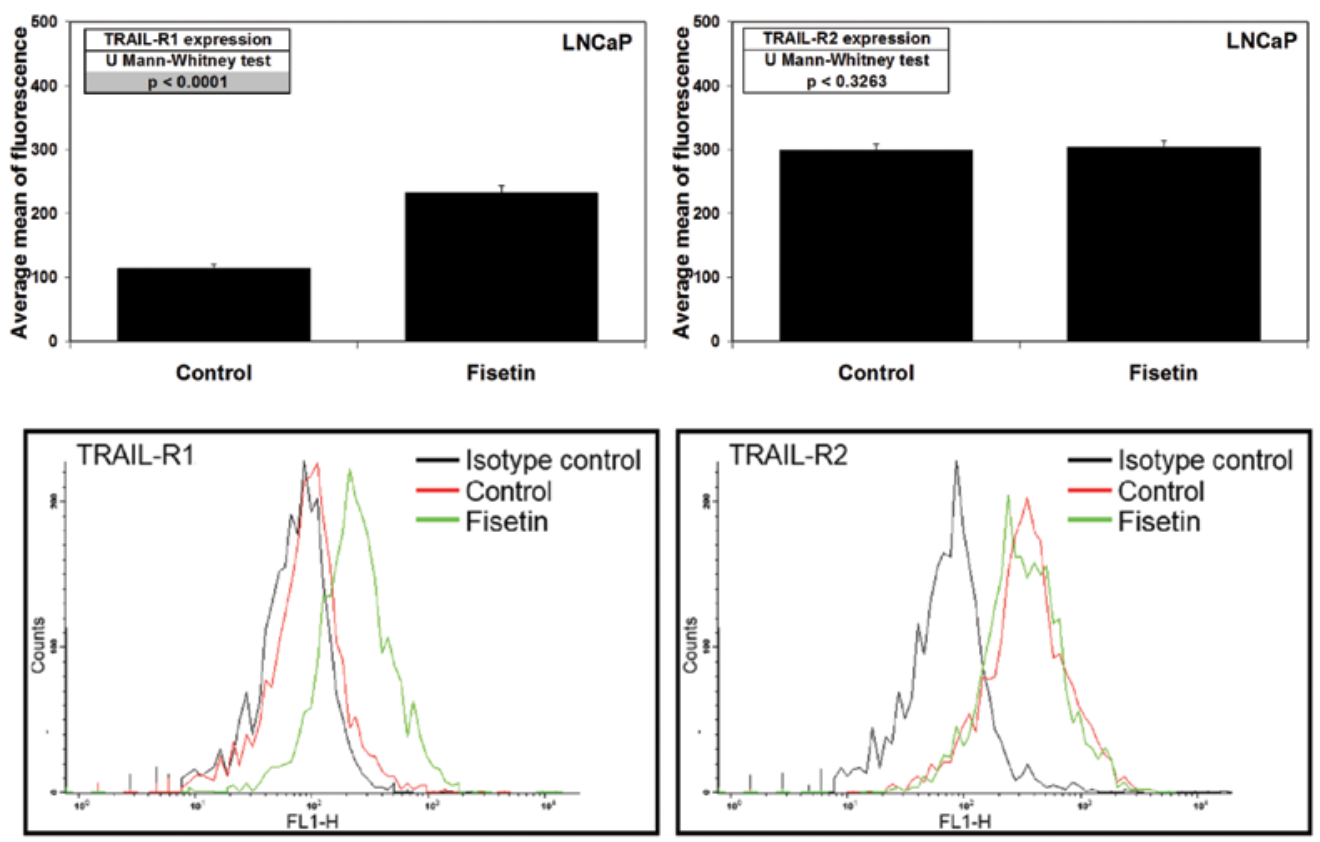

Figure 4. Effects of fisetin on death receptor expression in LNCaP prostate cancer cells. Cells were incubated for $24 \mathrm{~h}$ with $50 \mu \mathrm{M}$ fisetin. The surface expression of TRAIL-R1 and TRAIL-R2 on LNCaP cells was measured by flow cytometry. Representative histograms and the average mean fluorescence from three independent experiments were performed in duplicate $\mathrm{n}=6$. The values represent mean $\pm \mathrm{SD}(\mathrm{P}<0.0001$ fisetin compared to control with the Mann-Whitney $\mathrm{U}$ test).
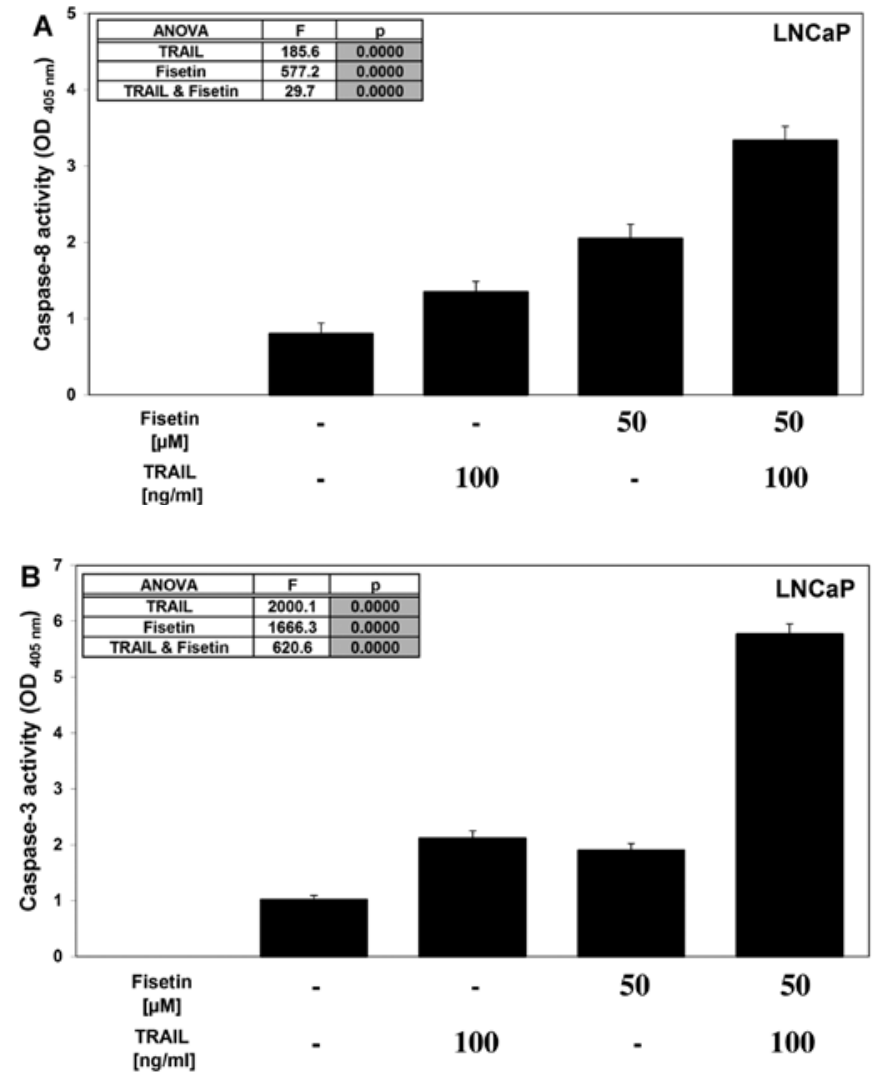

Figure 5. Effects of TRAIL in combination with fisetin on caspase activities in LNCaP prostate cancer cells. Assessment of intracellular (A) caspase-8 and (B) caspase-3 activity in LNCaP treated with $100 \mathrm{ng} / \mathrm{ml}$ TRAIL and/or $50 \mu \mathrm{M}$ fisetin for $24 \mathrm{~h}$. Caspase activities were measured by colorimetric protease assays based on the spectrophotometric detection of the chromophore p-nitroanaline ( $\mathrm{pNa}$ ) after cleavage from the labelled caspase substrates. The values represent the mean \pm SD of three independent experiments performed in duplicate $(\mathrm{n}=6)(\mathrm{P}<0.0001$ for TRAIL + fisetin compared to TRAIL or fisetin alone in ANOVA). which results in the recruitment and activation of caspase- 8 . TRAIL and fisetin alone activated caspase- 8 in cancer cells. Simultaneous incubation of LNCaP cells with TRAIL and fisetin markedly increased caspase- 8 activity (Fig. 5A). Caspase- 3 is an effector caspase that plays a central role in apoptosis. Co-treatment of cancer cells with TRAIL and fisetin significantly enhanced caspase-3 activity, compared to treatment with TRAIL or fisetin alone (Fig. 5B). Use of the pan-caspase inhibitor Z-VAD-FMK, the caspase- 8 inhibitor Z-IETD-FMK or the caspase-3 inhibitor Z-DEVD-FMK completely blocked the subsequent cell death induced by TRAIL in combination with fisetin. These findings demonstrate that fisetin is able to promote TRAIL-mediated apoptosis through a caspase cascade.

Effects of TRAIL and fisetin on the mitochondrial membrane potential $\left(\Delta \Psi_{m}\right)$ in LNCaP cells. Mitochondrial membrane depolarization is one of the first intracellular changes following the onset of apoptosis. We therefore, determined whether fisetin sensitizes cancer cells to TRAIL-induced mitochondrial dysfunction. Treatment of LNCaP cells with $100 \mathrm{ng} / \mathrm{ml}$ TRAIL or $50 \mu \mathrm{M}$ fisetin alone resulted in a small effect on the $\Delta \Psi \mathrm{m}(12.4 \pm 0.9$ and $17.8 \pm 1.0 \%$, respectively). The combination of TRAIL and fisetin enhanced $\Delta \Psi \mathrm{m}$ loss in a large percentage of cancer cells $(75.6 \pm 1.1 \%)$ and induced a significant disruption of the $\Delta \Psi \mathrm{m}$ (Fig. 6). These results suggest that the extrinsic apoptosis pathway is involved in LNCaP cells treated with TRAIL and fisetin.

Effects of fisetin and TRAIL on $N F-\kappa B$ activity in LNCaP cells. We examined the effects of fisetin and/or TRAIL on $\mathrm{NF}-\kappa \mathrm{B}$ activation in cancer cells (Fig. 7). We evaluated the binding activity of the p65 subunit in nuclear extracts with the 


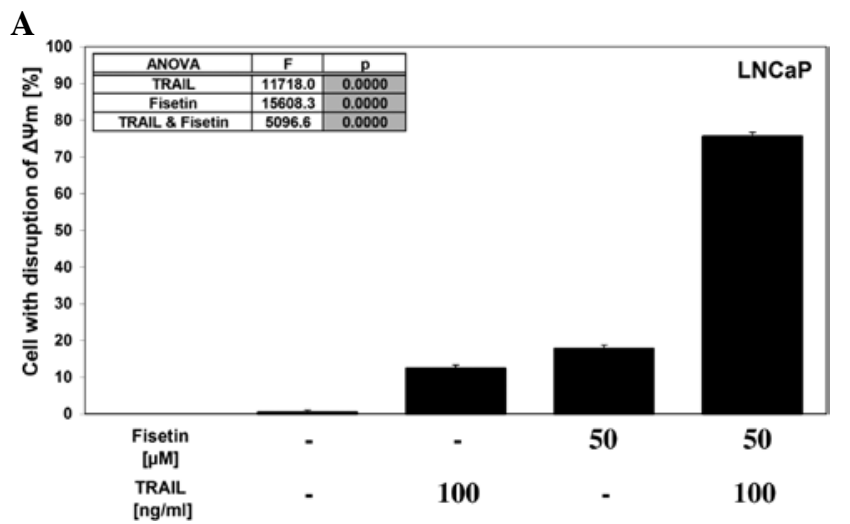

B
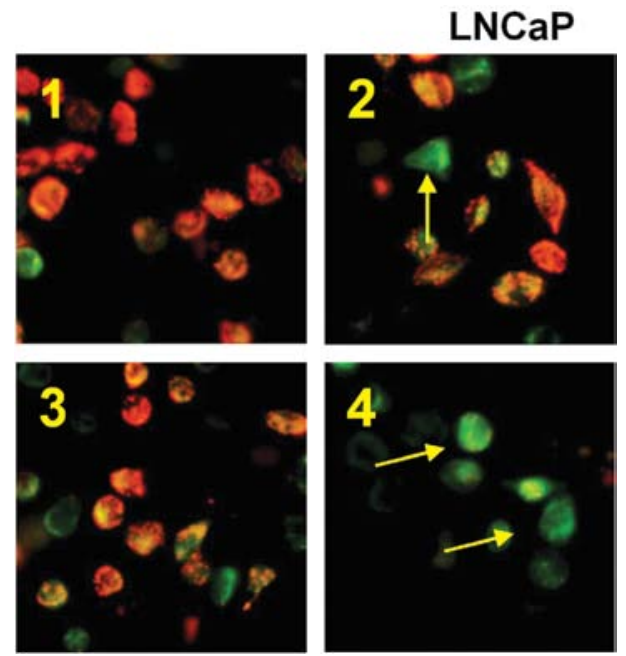

Figure 6. Effects of TRAIL in combination with fisetin on the mitochondria membrane potential $(\Delta \Psi \mathrm{m})$ in LNCaP prostate cancer cells. Cells were incubated for $24 \mathrm{~h}$ with $100 \mathrm{ng} / \mathrm{ml}$ TRAIL and/or $50 \mu \mathrm{M}$ fisetin. The values represent the mean $\pm \mathrm{SD}$ of three independent experiments performed in duplicate $(n=6)(P<0.001$ for TRAIL + fisetin compared to TRAIL or fisetin alone in ANOVA). (A) TRAIL in combination with fisetin induced loss of $\Delta \Psi \mathrm{m}$ in LNCaP cells. (B) Disruption of $\Delta \Psi \mathrm{m}$ in cancer cells was assessed by fluorescence microscopy of DePsipher staining: (1) control cells, (2) cells incubated with $100 \mathrm{ng} / \mathrm{ml}$ TRAIL, (3) cells incubated with $50 \mu \mathrm{M}$ fisetin, and (4) cells incubated with both $100 \mathrm{ng} / \mathrm{ml}$ TRAIL and $50 \mu \mathrm{M}$ fisetin. Red fluorescence is emitted from the red aggregates of DePsipher, which are formed within mitochondria of healthy cells. Green fluorescence reveals the monomeric form of the DePsipher molecule, which appears in the cytosol after mitochondrial membrane depolarisation (indicated by arrows).

ELISA-based TransAM NF- $\kappa$ B kit. Fisetin decreased the activity of $\mathrm{NF}-\kappa \mathrm{B}$ compared with the control. In contrast, TRAIL induced the activation of NF- $\kappa \mathrm{B}$ in LNCaP cells. Co-treatment of fisetin with TRAIL significantly decreased the $\mathrm{NF}-\kappa \mathrm{B}$ activity. The tested flavonol blocked the NF- $\kappa \mathrm{B}$ activation induced by TRAIL in prostate cancer cells and in this way overcame the resistance to TRAIL.

\section{Discussion}

The use of dietary polyphenols is becoming increasingly appreciated as an effective strategy in prostate cancer prevention. Recently, there has been major interest in the development of compounds of natural origin with chemopreventive activities $(20,25)$. Flavonoids isolated from fruits, vegetables, green and black tea, herbs, spices, propolis, beer and red wine are

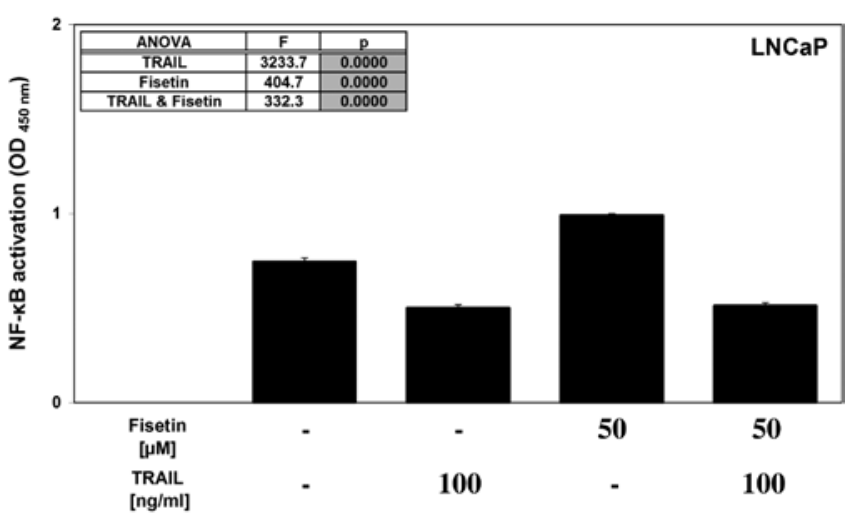

Figure 7. Effects of fisetin and TRAIL on NF- $\mathrm{NB}$ activity in LNCaP prostate cancer cells. The cancer cells were incubated for $24 \mathrm{~h}$ with $50 \mu \mathrm{M}$ fisetin and/or $100 \mathrm{ng} / \mathrm{ml}$ TRAIL. The values represent the mean \pm SD of three independent experiments performed in duplicate $(n=6)(P<0.0001$ for TRAIL + fisetin compared to TRAIL or fisetin alone in ANOVA). The effects of fisetin and/or TRAIL on the NF- $\kappa \mathrm{B}$ (p65) binding activity in nuclear extracts from LNCaP cells were measured using the ELISA-based TransAM NF- $\kappa$ B assay.

extensively researched for their health promoting potential. Epidemiological and preclinical findings confirm the anticancer and chemopreventive properties of flavonoids $(3,17-20)$.

TRAIL is an important component of the immune defence that causes apoptosis selectively in cancer cells (1). Dysregulation of apoptotic pathways is significant in the initiation and progression of prostate cancer $(25,26,39-41)$. LNCaP, DU145 and PC3 prostate cancer cells are resistant to TRAILmediated apoptosis $(5,11,28)$. Several in vitro tests suggest that the chemopreventive advantages of dietary flavonoids are associated with the enhancement of TRAIL-induced death in cancer cells $(3,42,43)$. Although the majority of prostate cancer cell lines are resistant to TRAIL-mediated apoptosis, TRAIL in combination with flavonoids results in the synergistic induction of cell death (9-14). Studies on the intracellular mechanism of TRAIL-mediated apoptosis may help overcome TRAIL-resistance and develop flavonoids-based approaches to prostate cancer prevention.

Apoptosis can be triggered by two major mechanisms: the intrinsic pathway involving mitochondrial dysfunction, and the extrinsic pathway stimulated by death receptors located on the cell membrane (1). The death receptors are essential for receptor-depending apoptosis in cancer $(6,7)$. We observed that fisetin enhanced TRAIL-apoptosis through up-regulation of TRAIL-R1 expression. Siddqui et al also showed that the green tea flavonoid epigallocathechin-3-gallate (EGCG) increases the expression of TRAIL-R1, thereby sensitizing LNCaP cells to TRAIL-mediated apoptosis (12). In prevalent cases, flavonoids can reverse TRAIL-resistance of prostate cancer cells, accompanied by the up-regulation of TRAILR2. Apigenin, baicalein, quercetin and biochanin-A influence TRAIL-R2 expression in prostate cancer cells $(9,10,13,37)$. Caspases comprise the central machinery in apoptosis. TRAIL-mediated programmed cell death is mainly executed by the extrinsic death receptor pathway, involving caspase- 8 as the initiator and caspase- 3 as the executor caspase. We observed that TRAIL or fisetin alone activated caspase- 8 and caspase-3 in LNCaP cells, whereas co-treatment with TRAIL 
and fisetin resulted in significant activation of both caspases in prostate cancer cells. Caspases 8,9 and 3 are activated by TRAIL in combination with EGCG in LNCaP cells or with quercetin in DU145 cells (11-13). These data provide further evidence that sensitization of prostate cancer cells to TRAIL by fisetin is achieved through a receptor- and caspase-dependent pathway. Our previous studies on prostate cancer cells confirmed the role of mitochondrial dysfunction caused by isoflavones and chalcones in TRAIL-mediated apoptotic pathways $(34,37,44)$. Therefore, we analysed the $\Delta \Psi \mathrm{m}$ in LNCaP cells after incubation with TRAIL and/or fisetin. TRAIL and fisetin co-treatment affected the extrinsic pathway in prostate cancer cells via significant reduction of $\Delta \Psi \mathrm{m}$ compared to TRAIL or fisetin alone.

Constitutively high expression of NF- $\kappa \mathrm{B}$ occurs frequently during cancer initiation and progression. De-regulated activation of NF- $\kappa B$ promotes survival of tumour cells and resistance to apoptosis. The activation of NF- $\mathrm{KB}$ in prostate cancer cells is associated with resistance to TRAIL-mediated death (45). Inhibition of NF- $\kappa B$ activation by fisetin in $\mathrm{LNCaP}$ cells augmented the apoptotic effect of TRAIL. Our findings confirm that the down-regulation of NF- $\mathrm{\kappa B}$ sensitizes prostate cancer cells to TRAIL in vitro.

Overcoming TRAIL-resistance by fisetin exposure in LNCaP cells was due to the up-regulation of TRAIL-R1, activation of caspase- 8 and caspase- 3 , loss of $\Delta \Psi \mathrm{m}$ and downregulation of NF- $\mathrm{KB}$. We showed for the first time that fisetin sensitizes androgen-dependent LNCaP cells or androgenindependent DU145 and PC3 cells to TRAIL-induced apoptosis. Interestingly, in androgen-independent prostate cancer cell lines the cytotoxic and apoptotic effects of TRAIL in combination with fisetin are lowest compared to androgendependent LNCaP cells. The results suggest that fisetin could be a promising chemopreventive agent for early-stage prostate cancer.

The apoptotic activity of fisetin alone has been established previously (46-48). Lim and Park demonstrated that fisetin increases the expression of TRAIL-R2, the cleavage of caspases $8,9,7,3$ and the permeability of the mitochondrial membrane with cytochrome c release in colon cancer HCT116 cells (47). Khan et al showed that fisetin activates caspases 8, 9, and 3, and causes mitochondrial release of cytochrome $\mathrm{c}$ into the cytosol in prostate cancer LNCaP cells (21). Chien et al (22) and $\mathrm{Li}$ et al (48) reported the suppression of NF- $\mathrm{\kappa B}$ activation in bladder cancer T24 cells and prostate cancer PC 3 cells incubated with fisetin. The data provide strong evidence, that this flavonol exhibits anticancer and chemopreventive properties. Our in vitro study indicates the significance of fisetin in prostate cancer chemoprevention strategies through enhancing the apoptosis inducing potential of TRAIL.

\section{Acknowledgements}

This study was supported by research grant KNW-1-087/10 from the Medical University of Silesia in Katowice (Poland).

\section{References}

1. Almasan A and Ashkenazi A: Apo2L/TRAIL: apoptosis signaling, biology and potential for cancer therapy. Cytokine Growth Factor Rev 14: 337-348, 2003.
2. Lee JY, Huerta-Yepez S, Vega M, Baritaki S, Spandidos DA and Bonavida B: The NO TRAIL to YES TRAIL in cancer therapy (Review). Int J Oncol 31: 685-691, 2007.

3. Szliszka E and Krol W: The role of dietary polyphenols in tumor necrosis factor -related apoptosis inducing ligand (TRAIL)induced apoptosis for cancer chemoprevention. Eur J Cancer Prev 20: 63-69, 2011.

4. Suliman A, Lam A, Datta R and Srivastava RK: Intracellular mechanisms of TRAIL: apoptosis through mitochondrialdependent and -independent pathways. Oncogene 20: 2122-2133, 2001.

5. Szliszka E, Czuba ZP, Bronikowska J, Mertas A, Paradysz A and Krol W: Ethanolic extract of propolis (EEP) augments TRAILinduced apoptotic death in prostate cancer cells. Evid Based Complement Alternat Med 2011: 1-11, 2011.

6. Baritaki S, Huerta-Yepez S, Sakai T, Spandidos DA and Bonavida B: Chemotherapeutic drugs sensitize cancer cells to TRAILmediated apoptosis: up-regulation of DR5 and inhibition of Yin Yang 1. Mol Cancer Ther 6: 1387-1399, 2007.

7. Baritaki S, Suzuki E, Umezawa K, Spandidos DA, Berenson J, Daniels TR, Penichet ML, Jazirehi AR, Pallandino M and Bonavid B: Inhibition of Yin Yang 1-dependent repressor activity of DR5 transcription and expression by the novel proteasome inhibitor NPI-0052 contributes to its TRAIL-ennhanced apoptosis in cancer cells. J Immunol 180: 6199-6210, 2008.

8. Lee SJ, Noh HJ, Sung EG, Song IH, Kim JY, Kwon TK and Lee TJ: Berberine sensitizes TRAIL-induced apoptosis through proteasome-mediated down-regulation of c-FLIP and Mcl-1 proteins. Int J Oncol 38: 485-492, 2011.

9. Horinaka M, Yoshida T, Shiraishi T, Nakata S, Wakada M and Sakai T: The dietary flavonoid apigenin sensitizes malignant tumor cells to tumor necrosis factor-related apoptosis-inducing ligand. Mol Cancer Ther 5: 945-951, 2006.

10. Tanaguchi H, Yoshida T, Horinaka M, Yasuda T, Goda AE, Konishi M, Wakada M, Kataoka K, Yoshikawa T and Sakai T: Baicalein overcomes tumor necrosis factor-related apoptosisinducing ligand resistance via two different cell specific pathways in cancer cells but not in normal cells. Cancer Res 68: 8918-8927, 2008.

11. Kim YH, Lee DH, Jeong JH, Guo ZS and Lee YJ: Quercetin augments TRAIL-induced apoptotic death: involvement of the ERK signal transduction pathway. Biochem Pharmacol 75: 1946-1958, 2008

12. Siddqui IA, Malik A, Adhami VM, Asim M, Hafeez BB, Sarfaraz S and Mukhtar H: Green tea polyphenol EGCG sensitizes human prostate carcinoma LNCaP cells to TRAILmediated apoptosis and synergistically inhibits biomarkers associated with angiogenesis and metastasis. Oncogene 27: 20552063, 2008

13. Jung YH, Heo J, Lee YJ, Kwon TK and Kim YH: Quercetin enhances TRAIL-mediated apoptosis in prostate cancer cells via increased protein stability of death receptor 5. Life Sci 86: 351-357, 2010.

14. Szliszka E, Czuba ZP, Mazur B, Sedek L, Paradysz A and Krol W: Chalcones enhance TRAIL-induced apoptosis in prostate cancer cells. Int J Mol Sci 11: 1-13, 2010.

15. Bronikowska J, Szliszka E, Czuba ZP, Zwolinski D, Szmydki B and Krol W: The combination of TRAIL and isoflavones enhances apoptosis in cancer cells. Molecules 15: 2000-2015, 2010.

16. Szliszka E, Gebka J, Bronikowska J and Krol W: Dietary flavones enhance the effect of tumor necrosis factor-related apoptosisinducing ligand (TRAIL) on bladder cancer cells. CEJ Urol 63: 138-143, 2010.

17. Ramos S: Effects of dietary flavonoids on apoptotic pathways related to cancer chemoprevention. J Nutr Biochem 18: 427-442, 2007.

18. Androutsopoulos VP, Ruparelia K, Aroo RRJ, Tsatsakis AM and Spandidos DA: CYP-1-mediated antiproliferative activity of dietary flavonoids in MDA-MB-468 breast cancer cells. Toxicology 264: 162-170, 2009.

19. Androutsopoulos VP, Papakyriakou A, Vourloumis D, Tsatsakis AM and Spandidos DA: Dietary flavonoids in cancer therapy and prevention: substrates and inhibitors of cytochrome P450 CYP1 enzymes. Pharmacol Ther 126: 9-20, 2010.

20. Syed DN, Suh Y, Afag F and Mukhtar H: Dietary agents for chemoprevention of prostate cancer. Cancer Lett 265: 167-176, 2008.

21. Khan N, Afag F, Syed DN and Mukhtar H: Fisetin, a novel dietary flavonoid, causes apoptosis and cell cycle arrest in human prostate cancer LNCaP cells. Carcinogenesis 29: 1049-1056, 2008. 
22. Chien C, Shen K, Huang J, Ko S and Shih Y: Antimetastatic potential of fisetin involves inactivation of the PI3K/Akt and JNK signaling pathways with down-regulation of MMP-2/9 expressions in prostate cancer PC 3 cells. Mol Cell Biochem 333: 169-180, 2010.

23. Haddad AQ, Fleshner N, Nelson C, Saour B, Musquera M, Venkateswaran V and Klotz L: Antiproliferative mechanisms of the flavonoids 2,2'-dihydrochalcone and fisetin in human prostate cancer cells. Nutr Cancer 62: 668-681, 2010.

24. Khan N, Asim M, Afag F, Zaid MA and Mukhtar H: A novel dietary flavonoid fisetin inhibits androgen receptor signaling and tumor growth in athymic nude mice. Cancer Res 68: 8555-8563, 2008.

25. Khan N, Adhami VM and Mukhtar H: Apoptosis by dietary agents for prevention and treatment of prostate cancer. Endocr Relat Cancer 17: 39-52, 2010

26. Sarkar FH, Li Y, Wang Z and Kong D: Novel targets for prostate cancer chemoprevention. Endocr Relat Cancer 17: 195-212, 2010.

27. Szliszka E, Bronikowska J, Czuba ZP and Krol W: Isoflavones augment the effect of tumor necrosis factor-related apoptosisinducing ligand (TRAIL) on prostate cancer cells. CEJ Urol 63 : 182-186, 2010.

28. Szliszka E, Bronikowska J, Majcher A, Miszkiewicz J and Krol W: Enhanced sensitivity of hormone-refractory prostate cancer cells to tumor necrosis factor-related apoptosis-inducing ligand (TRAIL) mediated cytotoxicity by taxanes. CEJ Urol 62: 29-34, 2009.

29. Ping SY, Hour TC, Lin SR and Yu DS: Taxol synergizes with antioxidants in inhibiting hormonal refractory prostate cancer cell growth. Urol Oncol 28: 170-179, 2010.

30. Szliszka E, Czuba ZP, Jernas K and Krol W: Dietary flavonoids sensitize HeLa cells to tumor necrosis factor-related apoptosisinducing ligand (TRAIL). Int J Mol Sci 9: 56-64, 2008.

31. Szliszka E, Czuba ZP, Domino M, Mazur B, Zydowicz G and Krol W: Ethanolic extract of propolis (EEP) enhances the apoptosis-inducing potential of TRAIL in cancer cells. Molecules 14: 738-754, 2009.

32. $\mathrm{Ku} \mathrm{JH}$, Seo SY, Kwak $\mathrm{C}$ and Kim HH: The role of survivin and Bcl-2 in zinc-induced apoptosis in prostate cancer cells. Urol Oncol: Sep 3, 2010 (Epub ahead of print), doi:10.1016/j. urolonc.2010.06.001.

33. Szliszka E, Czuba ZP, Sedek L, Paradysz A and Krol W: Enhanced TRAIL-mediated apoptosis in prostate cancer cells by the bioactive compounds neobavaisoflavone and psoralidin isolated from Psoralea corylifolia. Pharmacol Rep 63: 139-148, 2011.

34. Szliszka E, Czuba ZP, Mazur B, Paradysz A and Krol W: Chalcones and dihydrochalcones augment TRAIL-mediated apoptosis in prostate cancer cells. Molecules 15: 5336-5353, 2010.

35. Szliszka E, Zydowicz G, Janoszka B, Dobosz C, KowalczykZiomek G and Krol W: Ethanolic extract of Brazilian green propolis sensitizes prostate cancer cells to TRAIL-induced apoptosis. Int J Oncol 38: 941-953, 2011.
36. Szliszka E, Mazur B, Zydowicz G, Czuba ZP and Krol W: TRAIL-induced apoptosis and expression of death receptor TRAIL-R1 and TRAIL-R2 in bladder cancer cells. Folia Histochem Cytobiol 47: 579-585, 2009.

37. Szliszka E, Czuba ZP, Mertas A, Paradysz A and Krol W: The dietary isoflavone biochanin-A sensitizes prostate cancer cells to TRAIL-induced apoptosis. Urol Oncol doi:10.1016/j. urolonc.2011.01.019, 2011.

38. Hori T, Kondo T, Kanamori M, Tabuchi Y, Ogawa R, Zhao Q, Ahmed K, Yasuda T, Seki S, Suzuki K and Kimura T: Nutlin-3 enhances tumor necrosis factor-related apoptosis-inducing ligand (TRAIL)-induced apoptosis through up-regulation of death receptor 5 (DR5) in human sarcoma HAO cells and human colon cancer HCT116 cells. Cancer Lett 287: 98-107, 2010.

39. Soulitzis N, Karyotis I, Delakas D and Spandidos DA: Expression analysis of peptide growth factors VEGF, FGF2, TGFB1, EGF and IGF1 in prostate cancer and benign prostatic hyperplasia. Int J Oncol 29: 305-314, 2006.

40. Kawabata R, Oie S, Oka T, Takahashi M, Kanayama H and Itoh K: Hydroxyflutamide enhances cellular sensitivity to 5-fluorouracil by suppressing thymidylate synthase expression in bicalutamide-resistant human prostate cancer cells. Int J Oncol 38: 665-676, 2011.

41. Teiten MH, Gaascht F, Cronauer M, Henry E, Dicato M and Diederich M: Anti-proliferative potential of curcumin in androgendependent prostate cancer cells occurs through modulation of the Wingless signaling pathway. Int J Oncol 38: 603-611, 2011.

42. Ishibashi $M$ and Ohtsuki T: Studies on search for bioactive natural products targeting signaling leading to tumor cell apoptosis. Med Res Rev 28: 688-714, 2008.

43. Jacquemin G, Shirley S and Micheau O: Combining naturally occurring polyphenols with TNF-related apoptosis-inducing ligand: a promising approach to kill resistant cancer cells? Cell Mol Life Sci 67: 3115-3130, 2010.

44. Szliszka E and Krol W: Soy isoflavones augment the effect of TRAIL-mediated apoptotic death in prostate cancer cells. Oncol Rep doi: 10.3892/or.2011.1332, 2011.

45. Guseva NV, Taghiyev AF, Sturm MT, Rokhlin OW and Cohen MB: Tumor necrosis factor-related apoptosis-inducing ligand-mediated activation of mitochondria-associated nuclear factor-kappaB in prostatic carcinoma cell lines. Mol Cancer Res 2: 574-584, 2004.

46. Kim JY, Jeon YK, Jeon W and Nam MJ: Fisetin induces apoptosis in Huh7 cells via down-regulation of BIRC8 and Bcl2L2. Food Chem Toxicol 48: 8-9, 2010

47. Lim DY and Park JHY: Induction pf p53 contributes to apoptosis of HCT116 human colon cancer cells by dietary compound fisetin. Am J Physiol Gastrointest Liver Physiol 296: 1060-1068, 2009.

48. Li J, Cheng Y, Qu W, Sun Y, Wang Z, Wang Z and Tian B: Fisetin, a dietary flavonoid induces cell cycle arrest and apoptosis through activation pf p53 and inhibition of NF-kappa B pathways in bladder cancer cells. Basic Clin Pharmacol Toxicol 108: 84-94, 2011. 